\title{
Psychiatric Comorbidity of Smoking and Nicotine Dependence
}

\author{
Naomi Breslau ${ }^{1,2}$
}

\begin{abstract}
Recent epidemiologic studies have revealed that comorbidity of psychiatric disorders is far more pervasive than previously suspected. Strong associations have been reported between specific substance use disorders and between any mental disorder and any substance use disorder. This report focuses on comorbidity of nicotine dependence, a substance use disorder on which little epidemiologic information is available. Data come from an epidemiologic study of approximately 1000 young adults in southeast Michigan, in which the NIMH-DIS, revised according to DSM-III-R, was used. Lifetime prevalence of nicotine dependence was $20 \%$. Males and females with nicotine dependence had increased odds for alcohol and illicit drug disorders, major depression, and anxiety disorders, compared with nondependent smokers and nonsmokers combined. Major depression and any anxiety disorder were associated specifically with nicotine dependence. Increased odds for alcohol or illicit drug disorders were observed also in nondependent smokers, compared to nonsmokers. History of early conduct problems increased the odds for nicotine dependence among smokers. Potential mechanisms in the comorbidity of nicotine dependence are discussed.
\end{abstract}

KEY WORDS: Smoking; nicotine dependence; psychiatric comorbidity; major depression; any anxiety disorder; substance use disorders.

\section{INTRODUCTION}

The Epidemiologic Catchment Area Study (ECA), a large-scale multisite study of psychiatric disorders in the United States, revealed that comorbidity of psychiatric disorders is far more pervasive than previously suspected (Regier et al., 1990). Individuals with a history of one psychiatric disorder were much more likely than would be expected by chance to have a history of another disorder. The odds ratio between any mental disorder and alcoholism in the ECA was 2.7 , and that between any

\footnotetext{
${ }^{1}$ Department of Psychiatry and Division of Biostatistics and Research Epidemiology, Henry Ford Health Sciences Center, Detroit, Michigan; Department of Psychiatry, Case Western Reserve University School of Medicine, Cleveland, Ohio; and Department of Psychiatry, University of Michigan School of Medicine, Ann Arbor, Michigan.

${ }^{2}$ To whom correspondence should be addressed at Henry Ford Hospital, Psychiatry Research, 1 Ford Place, Detroit, Michigan 48202. Fax: (313) 556-8168.
}

mental disorder and illicit drug use disorder, 4.5. The relationship between alcoholism and any illicit drug use disorder was even stronger, with an odds ratio of 7.1 (Regier et al., 1990). The highest associations with alcoholism were observed for antisocial personality disorder [prevalence ratio (PR) $=19.6]$, illicit drug use disorder $(\mathrm{PR}=5.7)$, and bipolar disorder ( $\mathrm{PR}=5.4$ ) (Helzer et al., 1991). The epidemiologic data also revealed that the association between alcoholism and depression observed in clinical studies cannot be attributed fully to selection bias, as there was in these epidemiologic data a 1.5- to 2.0-fold increased odds for major depression in alcoholics. Nonetheless, the odds for illicit drug use disorders, bipolar disorder, and antisocial personality disorder (ASP) associated with alcoholism were far greater than for major depression (Helzer et al., 1991). Similar results emerged for comorbidity of illicit drug use disor- 
der, with ASP and bipolar disorder having the strongest associations with drug use disorder (PR $=10.6$ and 10.7, respectively) (Helzer et al., 1991). Illicit drug use disorder was also associated with major depression ( $\mathrm{PR}=3.5)$. The strong associations of these substance use disorders with ASP and bipolar disorder applied in both men and women.

No data are available in the ECA study on nicotine dependence, its prevalence in the population, or its association with other substance use and mental disorders. There are, however, data from two of the ECA sites on the prevalence of smoking and on the association of smoking with major depression and alcoholism (Glassman et al., 1990). Specifically, the odds ratio for ever smoking in subjects with Major Depression was 2.4, and that for alcoholism, 5.2 (Glassman et al., 1990).

In this report, I summarize findings on the association between nicotine dependence, as defined in the official psychiatric classification system, DSM-III-R [American Psychiatric Association (APA), 1987], and psychiatric disorders, based on data from a recent epidemiologic study of young adults in the Detroit metropolitan area.

\section{METHODS}

A random sample of 1200 was drawn from all 21 - to 30-year-old members of a 400,000 member health maintenance organization (HMO) in southeast Michigan. A total of 1007 respondents, 84\% of the sample, was interviewed at their homes from March through October 1989. The median age was 26 years; $61.7 \%$ were female, $80.7 \%$ were white, and $45 \%$ were married. A minority, $3.7 \%$, had less than high-school education, $21 \%$ had completed high school, $46 \%$ had some college education, and $29.3 \%$ were college graduates. Drawn from a list of members of a HMO, subscribers and dependents, the sample represents the population of this age in the area, excluding only the extremes of the socioeconomic range. Available reports on HMO populations indicate that the members generally represent the population of the geographic area, except that they are slightly more educated and healthier (Freeborn and Pope, 1982; McFarland et al., 1986). On indicators of general health and health behaviors, e.g., ratings of self-assessed health, prevalence of cigarette smoking, and alcohol and cocaine use, our sample resembles the U.S. population of comparable age, as described in na- tional reports (USDHHS, 1988; Schoenborn and Boyd, 1989).

The National Institute of Mental Health Diagnostic Interview Schedule (DIS), revised to cover DSM-III-R diagnoses (Robins et al., 1989), was used to gather information on psychiatric and substance use disorders. The Diagnostic Interview Schedule elicits information on symptoms of disorders experienced anytime in life. The information is used to estimate lifetime and period (e.g., 1-year) prevalence of psychiatric disorders. The lifetime prevalence of a disorder is defined as the proportion of persons in the sample who have ever experienced the disorder up to the time of the interview. One-year (or current) prevalence is determined based on information on the recency of the last episode (e.g., for major depression) or symptom of a disorder (e.g., for nicotine dependence). The section on nicotine dependence begins with a screen question that inquires whether or not the respondent ever smoked daily for a month or more. Persons who answer negatively are defined as nonsmokers. The remainder of the section inquires about DSM-III-R symptoms of nicotine dependence.

The diagnostic definition of psychoactive substance use disorders in DSM-III-R and ICD-9 reflect current consensus in the field of addiction on the cardinal characteristics of substance use disorder (Rounsaville and Kranzler, 1989). At the core of the category is the construct of dependence, defined as a cognitive, behavioral, and physiologic cluster that characterizes compulsive use of all substances. The adoption of a unitary definition (modified for certain substances) is based on the assumption that principles established in research on some addictions (e.g., alcohol) apply also to other, less extensively researched ones (e.g., nicotine). One important principle incorporated into the DSM-III-R is the emphasis on the level of severity of dependence as an essential clinical feature. This principle has received considerable support in research on alcoholism, with regard to the cause, prognosis, and treatment of the disorder (Cloninger, 1987; Hesselbrock et al., 1985; Rounsaville et al., 1987).

The diagnostic criteria of DSM-III-R nicotine dependence in the DIS algorithms exclude two symptoms from the general criteria of psychoactive substance use disorder (APA, 1987). They are failure to fulfill major role obligations and excessive 
time spent in getting the substance or recovering from its effect. Mild nicotine dependence is defined as the presence of three or four dependence symptoms, but not including interference in social, occupational, or recreational functioning. Moderate dependence is defined by five or six dependence symptoms, or three symptoms when one is interference in functioning. Severe dependence requires the presence of all seven dependence symptoms that apply to nicotine dependence.

Previous research has generally used the Fagerström (1978) Tolerance Questionnaire (FTQ) to measure nicotine dependence. In contrast with the DSM-III $\mathrm{R}$ definition of nicotine dependence as a cognitive, behavioral, and physiologic construct, the FTQ is a measure of physiologic dependence. While the two definitions overlap, they cannot be expected to identify the same subset of smokers as nicotine dependent. The implications of the disparity for the association with psychiatric disorders is unclear.

\section{RESULTS}

\section{Lifetime Prevalence of Smoking, Nicotine Dependence, and Psychiatric Disorders}

Of the total sample of young adults, $40.9 \%$ reported that they had smoked daily for 1 month or more at any time in their life and $50 \%$ of those who had ever smoked daily met criteria for nicotine dependence in lifetime (Table 1). The overall prevalence of nicotine dependence-20\%-was close to the prevalence of alcohol dependence- $18.2 \%$. However, unlike alcohol dependence and illicit drug dependence, which varied widely between the sexes, nicotine dependence was just as frequent in women as in men (Table 1). Both major depression and any anxiety disorder were more frequent in women than in men, findings that are congruent with other reports on sex differences in these disorders.

Table II presents the lifetime prevalence of smoking and nicotine dependence by race and level of education. Smoking daily for a month or more was more frequent in whites than in blacks. Furthermore, the lifetime prevalence of nicotine dependence in white smokers was higher than in black smokers, 55 vs $31 \%$, respectively. The race difference in the prevalence of smoking among young adults in this and other epidemiologic stud-
Table I. Lifetime Prevalence of Smoking, Substance Dependence, Major Depression, and Any Anxiety Disorder (Rate/100)

\begin{tabular}{lccc}
\hline & $\begin{array}{c}\text { Total } \\
(N=1007)\end{array}$ & $\begin{array}{c}\text { Males } \\
(N=386)\end{array}$ & $\begin{array}{c}\text { Females } \\
(N=621)\end{array}$ \\
\hline Smoking daily $\geq 1$ month & 40.9 & 38.1 & 42.6 \\
Nicotine dependence & 20.0 & 19.4 & 20.4 \\
Alcohol dependence & 18.2 & 28.2 & 11.9 \\
Illicit drug dependence & 10.2 & 15.5 & 6.9 \\
Major depression $_{\text {Any anxiety disorder }}{ }^{a}$ & 13.4 & 9.6 & 15.8 \\
Snd $^{2}$ & 30.4 & 20.2 & 36.7 \\
\hline
\end{tabular}

${ }^{a}$ Includes phobia, panic disorder, GAD, and OCD.

Table II. Lifetime Prevalence of Smoking and Nicotine Dependence by Race and Education (Rate/100)

\begin{tabular}{lcc}
\hline & Smoking $^{a}$ & Nicotine dependence \\
\hline Race & & \\
$\quad$ White & 41.3 & 22.6 \\
Black & 29.9 & 9.3 \\
Education & & \\
$\quad<$ HS & 78.4 & 51.4 \\
HS & 55.2 & 27.4 \\
Part college & 41.1 & 21.0 \\
College & 19.6 & 9.5 \\
\hline
\end{tabular}

${ }^{a}$ Smoking daily for 1 month or more in lifetime.

ies represents a reversal from the pattern in older adults, in whom smoking is more prevalent among blacks than whites. The race difference in the proportion of smokers who met criteria for nicotine dependence has not been previously reported (Andreski and Breslau, 1993). A strong inverse association was found between level of education and lifetime prevalence of daily smoking as well as nicotine dependence. The prevalence estimates of smoking and nicotine dependence in persons who completed college were approximately one-half of those in persons with less than college education.

\section{Comorbidity of Nicotine Dependence with Alcohol, Illicit Drugs, Major Depression, and Anxiety}

Because of the marked sex differences in the prevalence of substance use disorders other than nicotine dependence, major depression, and any anxiety disorder, the associations between nicotine dependence and these disorders were estimated separately in males and females (Table III). The lifetime prevalence proportions of alcohol use dis- 
Table III. Sex-Specific Comorbidity with Nicotine Dependence: Percentages and Odds Ratios with 95\% Confidence Intervals $(\mathrm{CI})^{a}$

\begin{tabular}{lccccccc}
\hline & \multicolumn{2}{c}{ Males } & & \multicolumn{2}{c}{ Females } \\
\cline { 2 - 3 } & $\begin{array}{c}\text { Nicotine } \\
\text { dependence } \\
(N=75)\end{array}$ & $\begin{array}{c}\text { No } \\
\text { dependence } \\
(N=311)\end{array}$ & & & $\begin{array}{c}\text { Nicotine } \\
\text { dependence } \\
(N=127)\end{array}$ & $\begin{array}{c}\text { No } \\
\text { dependence } \\
(N=494)\end{array}$ & OR (95\% CI) \\
\hline Alcohol A/D & 45.3 & 29.9 & $1.9(1.2-3.3)$ & 25.2 & 11.5 & $2.6(1.6-4.2)$ \\
Illicit drugs A/D & 44.0 & 10.6 & $6.6(3.7-11.8)$ & 18.9 & 5.5 & $4.0(2.2-7.3)$ \\
Major depression & 21.3 & 6.8 & $3.8(1.8-7.6)$ & 29.9 & 12.2 & $3.1(1.9-4.9)$ \\
Any anxiety & 32.0 & 17.4 & $2.2(1.3-3.9)$ & 55.1 & 32.0 & $2.6(1.8-3.9)$ \\
\hline
\end{tabular}

${ }^{a}$ No dependence includes nondependent smokers and never smokers.

Table IV. Percentages with Psychiatric Disorders by Smoking Status

\begin{tabular}{lccc}
\hline & Dependent & Nondependent Nonsmokers \\
& $(N=202)$ & $(N=209)$ & $(N=595)$ \\
\hline Alcohol dependence & 27.2 & 23.0 & 13.5 \\
Cannabis dependence & 17.8 & 11.0 & 3.0 \\
Cocaine dependence & 8.9 & 4.8 & 0.8 \\
Major depression & 26.7 & 12.0 & 9.4 \\
Any anxiety & 46.5 & 33.5 & 23.9 \\
\hline
\end{tabular}

order, illicit drug use disorder, major depression, and any anxiety were significantly higher in males and females who were nicotine dependent than in nondependent counterparts. Although alcohol and illicit drug use disorders were more frequent in males than females, their relationship with nicotine dependence did not vary significantly between the sexes. Further, major depression and any anxiety, psychiatric disorders in which women predominate, were associated with nicotine dependence to a similar extent in males and females.

Combining data on males and females, we examine the extent to which comorbidity with psychiatric disorders varied between dependent and nondependent smokers. The sample was divided into three groups: nicotine-dependent smokers, nondependent smokers, and nonsmokers. Table IV presents the prevalence proportions of alcohol dependence, cannabis dependence, cocaine dependence, major depression, and any anxiety disorder in the three groups. Table $\mathrm{V}$ presents sex-adjusted odds ratios as estimates of the associations. The odds ratios for major depression and any anxiety were adjusted also for other substance dependencies. An examination of Table IV reveals that the prevalence estimates of alcohol, cannabis, and co-
Table V. Sex-Adjusted Odds Ratios (OR) and 95\% Confidence Intervals (CI) for Psychiatric Disorders in Dependent and Nondependent Smokers

\begin{tabular}{lcc}
\hline & \multicolumn{2}{c}{ OR $(95 \% \mathrm{CI})^{a}$} \\
\cline { 2 - 3 } & $\begin{array}{c}\text { Dependent smokers } \\
\text { vs nonsmokers }\end{array}$ & $\begin{array}{c}\text { Nondendent } \\
\text { smokers } \\
\text { vs nonsmokers }\end{array}$ \\
\hline Alcohol dependence & $2.7(1.8-4.0)$ & $2.1(1.4-3.2)$ \\
Cannabis dependence & $8.0(4.3-14.8)$ & $4.3(2.2-8.2)$ \\
Cocaine dependence & $11.8(4.3-32.2)$ & $6.5(2.2-19.5)$ \\
Major depression & $2.9(1.9-4.5)$ & $1.1(0.6-1.8)$ \\
Any anxiety & $2.4(1.7-3.5)$ & $1.4(1.0-2.0)$ \\
\hline
\end{tabular}

${ }^{a}$ ORs for major depression and any anxiety adjusted also for other substance dependencies.

caine dependence were higher in persons with nicotine dependence than in nondependent smokers. However, even nondependent smokers had significantly increased odds for these substance use disorders, compared to nonsmokers, as Table V reveals. For example, sex-adjusted odds ratios for alcohol dependence were 2.7 and 2.1 in dependent and nondependent smokers, respectively. In contrast, major depression and any anxiety disorder had significantly increased associations only with nicotine dependence, whereas the associations with nondependent smoking were not significant, when adjusted also for other substance dependencies.

Additional analysis was performed to estimate the associations of nicotine dependence with major depression and any anxiety disorder according to level of severity of nicotine dependence (Breslau et al., 1991). Significantly higher prevalence proportions of major depression and any anxiety disorders were found in persons with moderate than mild nicotine dependence. (None of the dependent smokers 
met criteria for severe dependence.) The odds ratio for major depression in moderate vs mild nicotine dependence was 2.7 (95\% CI, 1.4-5.1), and that for any anxiety disorder, $2.8(95 \% \mathrm{CI}, 1.6-5.1)$.

These data indicate that the association with alcohol and illicit drug use disorders are not specific to nicotine dependence and apply also to nondependent smoking. In contrast, major depression and any anxiety disorder appear to be specific to nicotine dependence. The finding of a unique association between these mental disorders and nicotine dependence (rather than smoking per se) has some antecedents in earlier findings on other substance use disorders. Regier et al. (1990) reported stronger associations for anxiety and affective disorders with DSM-III dependence rather than abuse of alcohol and other psychoactive substances.

\section{Nicotine Dependence and Early Conduct Problems}

While antisocial personality disorder was not measured in this study, we obtained information on history of early conduct problems. History of six behavior problems before age 15 was used to measure early conduct problems: expelled or suspended from school, starting fights, truancy, running away from home, trouble with teachers or principal because of misbehavior, and telling lies. Using survival analysis, with age of smoking initiation, sex, and race as covariates, we found that, among persons who have ever smoked a cigarette, the probability of nicotine dependence was significantly higher in persons with a history of one or more early conduct problems than in those with no such history [hazards ratio $=1.8(95 \% \mathrm{CI}, 1.3-2.4) ; p$ $<.001]$ (Breslau et al., 1993).

History of early conduct problems was unrelated to having ever smoked a cigarette. However, history of early conduct problems was associated with early smoking initiation, specifically, smoking the first cigarette before age 14 . Table VI presents rates of each of the six behavior problems across three age of smoking initiation groups and those who have never smoked a cigarette. The proportions with history of one problem or more across these groups are included as well. The odds ratios for history of one or more conduct problems in persons who initiated smoking before age 14 vs the two older smoking initiation groups or never smokers ranged from $2.0(95 \% \mathrm{CI}, 1.4-2.8)$ to $2.4(95 \%$
Table VI. Early Conduct Problems and Early Smoking Initiation Rate $/ 100^{2}$

\begin{tabular}{|c|c|c|c|c|c|c|}
\hline & $\begin{array}{c}\leq 13 \\
(256)^{b}\end{array}$ & $\begin{array}{l}14-16 \\
(292)\end{array}$ & $\begin{array}{c}\geq 17 \\
(184)\end{array}$ & $\begin{array}{l}\text { Never } \\
(259)\end{array}$ & $x^{2}$ & $P$ value \\
\hline Expelled/suspended & 19.4 & 10.9 & 9.2 & 8.1 & 18.6 & $<0.0001$ \\
\hline Starting fights & 31.8 & 21.1 & 20.6 & 18.9 & 13.7 & 0.002 \\
\hline Truancy & 26.4 & 17.0 & 16.3 & 11.6 & 20.1 & $<0.0001$ \\
\hline Running away & 5.4 & 1.4 & 3.8 & 1.5 & 10.5 & 0.015 \\
\hline Trouble at school & 17.4 & 8.5 & 7.1 & 6.6 & 21.7 & $<0.0001$ \\
\hline Telling lies & 18.2 & 14.3 & 13.0 & 12.0 & 4.6 & 0.208 \\
\hline One or more problems & 61.6 & 44.5 & 40.8 & 40.2 & 30.6 & $<0.0001$ \\
\hline
\end{tabular}

${ }^{a}$ Results of seven independent cross-tabulations.

${ }^{b} N$ given in parentheses.

CI, 1.7-3.4). Thus, history of early conduct problems is associated with increased odds for early smoking initiation. Furthermore, independent of its association with early smoking, history of early conduct problems increased the risk of becoming nicotine dependent. The results of this study, taken together with those from previous studies, suggest that childhood conduct problems and antisocial behaviors in late adolescence or young adulthood are associated with the development of substance use disorders, not merely substance use.

\section{Potential Mechanisms in the Relationship Between Smoking and Other Substance Dependencies}

An accumulating body of research on the stage sequences of substance use has suggested that, for most users, cigarettes or alcohol play an early role in the process leading to abuse of illicit drugs (Kandel and Logan, 1984). The finding that tobacco and alcohol play an early role in the progression of substance use and disorders, that is, that they are "gateway" drugs, is not surprising. Their use is socially accepted for adults and they are widely available to children and adolescents. The drug sequencing model, which postulates a progression from licit to illicit substances, would predict associations between smoking and illicit drug use disorders of the sorts observed in this study. It would also predict a somewhat stronger association between nicotine dependence - a more advanced stage than nondependent smoking-with dependence on illicit substances-a later stage in the overall progression. Additionally, the observed association between nicotine dependence and al- 
cohol dependence is consistent with a model that characterizes the early stages of the onset process by an initial sampling of either substance, followed by the initial sampling of the other, followed by an experience with drunkenness and then a more advanced use of either substance or both (Collins et $a l ., 1994)$. As to the nature of the relationship between smoking and use of or dependence on other substances, there is little basis for inferring a causal role. One possible explanation is that adolescents who are sensation seekers start their substance use experience with substances that are readily available, primarily tobacco and alcohol. Another explanation is that early use of tobacco indicates inadequate parental monitoring, a factor associated with experimentation with other substances (Chilcoat et al., 1995). Evidence of familial and genetic factors in the cooccurrence of smoking, drinking, and illicit drug use might also account for the lifetime associations across a variety of substance use disorders (Heath et al., 1995).

\section{Potential Mechanisms in the Relationship Between Nicotine Dependence and Major Depression}

Recent research on smoking and psychopathology has focused primarily on the smoking-major depression association (Glassman, 1993). Glassman et al. (1988) reported that among smokers attending a smoking cessation clinic, those with a history of past major depression failed to stop smoking at more than twice the rate of those free of such history. A report based on data from the National Health and Nutrition Epidemiologic Survey confirmed the lower rate of quitting among smokers with a history of depressive symptoms (Anda et al., 1990). This and other epidemiologic studies appear to provide the needed support for the report from the clinical study (Glassman, 1993). However, a lower quitting rate in depressed smokers cannot account for the lifetime association between smoking and major depression or depressive symptoms. Breslau et al. (1993) reported that smokers with a history of major depression were more likely than other smokers to become nicotine dependent and to progress to a more severe level of dependence over a 15-month follow-up period. Conversely, persons with a history of nicotine dependence had an increased incidence of major depression during the same period of observation.
The bidirectional association between nicotine dependence and major depression, with each disorder increasing the odds for first onset of the other, suggests the possibility of a noncausal mechanism, such as an underlying common predisposition. Evidence from a twin study by Kendler et al. (1993) suggests that the association between smoking and major depression is due largely to genetic factors. They hypothesized that genetically influenced personality traits might contribute to the association between smoking and major depression. Evidence that neuroticism might be the trait involved in this association has been reported, based on retrospective data (Breslau et al., 1994). Prospective studies are needed to provide a stronger test of this hypothesis.

\section{ACKNOWLEDGMENTS}

This research was supported by Grant MH48802 and a Research Scientist Development Award KO2 MH-00380 from the National Institute of Mental Health, Bethesda, MD.

\section{REFERENCES}

American Psychiatric Association, Committee on Nomenclature and Statistics (1987). Diagnostic and Statistical Manual of Mental Disorders, Revised Third Edition, American Psychiatric Association, Washington, DC.

Anda, R. F., Williamson, D. F., Escobedo, L. G., Mast, E. E., Giovino, G. A., and Remington, P. L. (1990). Depression and the dynamics of smoking. JAMA 264:1541-1545.

Andreski, P., and Breslau, N. (1993). Smoking and nicotine dependence in young adults: Differences between blacks and whites. Drug Alcohol Depend. 32:119-125.

Breslau, N., Kilbey, M. M., and Andreski, P. (1991). Nicotine dependence, major depression, and anxiety in young adults. Arch. Gen. Psychiatry 48:1069-1074.

Breslau, N., Fenn, N., and Peterson, E. L. (1993a). Early smoking initiation and nicotine dependence in a cohort of young adults. Drug Alcohol Depend. 33:129-137.

Breslau, N., Kilbey, M. M., and Andreski, P. (1993b). Vulnerability to psychopathology in nicotine-dependent smokers: An epidemiologic study of young adults. $\mathrm{Am}$. $J$. Psychiatry 150:941-946.

Breslau, N., Kilbey, M. M., and Andreski, P. (1994). DSMIII-R nicotine dependence in young adults: prevalence, correlates, and associated psychiatric disorders. Addiction 89:743-754.

Chilcoat, H. D., Dishion, T. J., and Anthony, J. (1995). Parent monitoring and the incidence of drug sampling in urban elementary school children. Am. J. Epidemiol. 141:25-31.

Cloninger, C. R. (1987). Neurogenetic adaptive mechanisms in alcoholism. Science 236:41-416.

Collins, L. M., Fidler, P. L., Wugalter, S. E., and Long, J. L. (1994). Crossvalidation of latent class models of early substance use onset. Multivar. Behav. Res. (in press). 
Fagerström, K. O. (1978). Measuring degree of physical dependency to tobacco smoking with reference to individualization of treatment. Addict. Behav. 3:235-241.

Freeborn, D. K., and Pope, C. R. (1982). Health status, utilization and satisfaction among enrollees in three types of private health insurance plans. Group Health $J$ 3:4-1 1 .

Glassman, A. H. (1993). Cigarette smoking: Implications for psychiatric illness. Am. J. Psychiatry 150(4):546-553.

Glassman, A. H., Stetner, F., Walsh, B. T., Raizman, P. S., Fleiss, J. L., Cooper, T. B., and Covey, L. S. (1988). Heavy smokers, smoking cessation and clonidine: results of a double-blind, randomized trial. JAMA 259:28632866.

Glassman, A. H., Helzer, J. E., Covey, L. S., Cottler, L. B., Stetner, F., Tipp, J. E., and Johnson, J. (1990). Smoking, smoking cessation, and major depression. JAMA 264: $1546-1549$.

Heath, A. C., Madden, P. A. F., Slutske, W. E., and Martin, N. G. (1995). Personality and the inheritance of smoking behavior: A genetic perspective. Behav Genet. 25:103117.

Helzer, J. E., Burnam, A., and McEvoy, L. T. (1991). Alcohol abuse and dependence. In Robins, L. N., and Regier, D. A. (eds.), Psychiatric Disorders in America, The Free Press, New York.

Hesselbrock, M. N., Meyer, R. E., and Keener, J. J. (1985) Psychopathology in hospitalized alcoholics. Arch. Gen. Psychiatry 42:1050-1055.

Kandel, C. B., and Logan, J. A. (1984). Patterns of drug use from adolescence to early adulthood. I. Periods of risk for initiation, stabilization and decline in drug use from adolescence to early adulthood. Am. J. Public Health 74: $660-666$.
Kendler, K. S., Neale, M. C., MacLean, C. J., Heath, A. C., Eaves, I. J., and Kessler, R. C. (1993). Smoking and major depression: A causal analysis. Arch. Gen. Psychiatry 50:36-43.

McFarland, B. H., Freeborn, D. K., Mulloly, J. P., and Pope, C. R. (1986). Utilization patterns and mortality of HMO enrollees. Med. Care 24:200-208.

Regier, D. A., Farmer, M. E., Rae, D. S., Locke, B. Z., Keith, S. J., Judd, L. L., and Goodwin, F. K. (1990). Comorbidity of mental disorders with alcohol and other drug abuse: Results from the Epidemiologic Catchment Area (ECA) Study. JAMA 264(19):2511-2518.

Robins, L. N., Helzer, J. E., Cottler, L., and Golding, E. (1989). NIMH Diagnostic Interview Schedule, Version III Revised, Washington University, St. Louis, MO.

Rounsaville, B. J., and Kranzler, H. R. (1989). The DSM-III$\mathrm{R}$ diagnosis of alcoholism. In Tasman, A., Hales, R. E., and Frances, A. J. (eds.), Review of Psychiatry, American Psychiatric Press, Washington, DC, Vol. 8, pp. 323-340.

Rounsaville, B. J., Dolnsky, Z. S., Babor, T. F., and Meyer, R. E. (1987). Psychopathology as a predictor of treatment outcome in alcoholics. Arch. Gen. Psychiatry 44:505513.

Schoenborn, C. A., and Boyd, G. M. (1989). Smoking and other tobacco use: United States 1987. Vital Health Stat. 10.

Skinner, H. A., and Allen, B. A. (1982). Alcohol dependence syndrome: measurement and validation. J. Abnorm. Psychol. 91:199-209.

U.S. Department of Health and Human Services (1988). National Household Survey on Drug Abuse: Main Findings, 1985, USDHHS Publ. ADM-1586, National Institute on Drug Abuse, Washington, DC. 